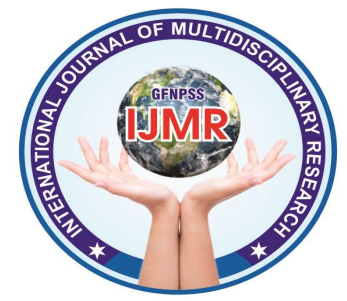

\title{
A STUDY TO ASSESS A LEVEL OF DEPRESSION AMONG CANCER PATIENT
}

\author{
MR. DEEPENDER BISHNOI ${ }^{1}$, MR VINIT KUMAR RAMAWAT ${ }^{2}$ \\ ${ }^{1}$ Nursing officer, AIIMS Jodhpur \\ ${ }^{2}$ Associate Professor, Metro College of Nursing,
}

\section{Corresponding Email: Vicky.aryan21@gmail.com}

\begin{abstract}
Background: Depression was major problem with cancer patients, it is not only affect psychological health but also negative impact on patients social life and their family. Aims \& Objectives: The aim of this study to assess the association between demographic data and level of depression among cancer patient.
\end{abstract}

Material and Methods: The descriptive survey approach was applied in the present study. Only 120 samples were employed by convenience non probability sampling technique. Results: According to depression rating scale, 38(31\%) had no depression, 65 (54\%) had mild depression and 17(15\%) moderate depression and none of sample was in severe depression stage. Additionally, there was no association between demographic variables like Age, Gender, Time of duration, mode of treatment and significant association between educations, family support with level of depression.

Conclusion: The study concluded that some cancer patients are always in depression stage. Any type of interventional program or counselling session for cancer patients regarding depression will effective to reduce Depression level and also develop coping strategies.

Keyword: Assess, Level of Depression, Cancer

\begin{tabular}{ccc}
\hline Received & Accepted & Available online \\
\hline $16 / 09 / 2021$ & $24 / 09 / 2021$ & $03 / 10 / 2021$ \\
\hline
\end{tabular}

\section{INTRODUCTION}

Cancer is one of the leading causes of morbidity and mortality worldwide, with approximately 14 million new cases.

Depression is the most common mental disorder worldwide. Nearly 350 million people are affected from depression. The prevalence of depression is higher in developing countries compare to developed 


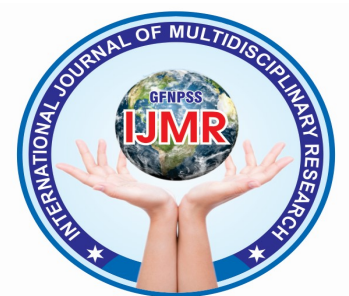

countries. ${ }^{1}$ The cancer has various physical

different levels of stress and emotional and psychological problems. ${ }^{2}$

The infections not only cause a significant amount of morbidity and mortality, but they also greatly increase health-care costs. $^{3}$ upsets. Patients who are receiving palliative care for cancer may have frequent feelings of depression and anxiety, leading to much lower quality of life. Sadness and grief are normal reactions Cancer not only affects organs system physically but can also affect the mind as a psychiatric disorder, depressive disorders and symptoms are common in cancer patients(Up to $38 \%$ is having major depression). It worsens the course of cancer treatment, persist long after cancer therapy, and reoccur with the reoccurrence of cancer and significantly on quality of life. ${ }^{4}$

Depression is seen in many cancer patients approximately $25 \%$ of palliative care patients. A matter of fact there are physical, social, emotional, and spiritual burdens placed upon cancer patients. They and their families require adjustment, coping, and adaptation to their living with a number of psychological, social interpersonal and economic levels of functioning. ${ }^{5}$

Depression is a disabling illness that affects about $15 \%$ to $25 \%$ of cancer patients. It affects men and women with cancer equally. People who face a diagnosis of cancer will experience to the crisis faced during cancer and will be experienced at times by all people.

An important part of cancer care is the recognition of depressing that needs to be treated. in an effort to reduce the occurrence of depression among cancer patients, special attention is needed for changes in the psychological status in patients with knowledge about their diagnosis and patients in advanced disease stage.

Good communication within the family reduces anxiety. Depression can amplify the intensity of pain and can diminish one's ability to cope up with life. Depression can lead to difficulty in decision making at this critical time of one's life. Pain is a major factor which cause distress to the patient (TATA). Cancer is a devastating disease. Awareness of this disorder tremendously impacts an individual's life, creating a host of changes to occur.

Disturbance of life plans, Fear of death, variations in body self-esteem and image, 


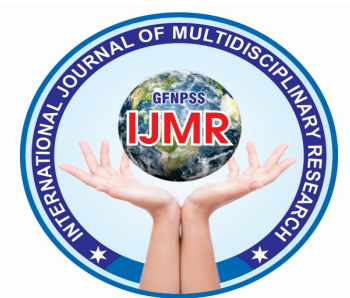

changes in lifestyle and social role and financial concerns are very important issues for a patient who diagnose with cancer, yet serious anxiety and depression isn't experienced by everybody who is diagnosed with cancer. Even as cancer patients require ongoing assessment for anxiety and depression throughout their treatment. ${ }^{9,10}$

screening of depression in cancer patients is very important, there is lack of previous study that deal with the prevalence of depression among cancer patients in Rajasthan, therefore this research was performed to assess level of depression cancer patients.

\section{AIMS \& OBJECTIVES}

The aim of this study to assess level of depression among cancer patient association it with demographic data

\section{MATERIALS AND METHODS}

This descriptive survey approach was using with non- probability convenient sampling technique. The study was done at Periwal Nursing Home. Ethical permission was taken. The descriptive survey approach was applied in the present study. Only 120 samples were employed by convenience non probability sampling technique. Purpose of the study was explained to the topic. Informed written consent was taken from each subject. A self-rating depression scale was prepared by investigator to assess the extent of depression among cancer patient. Structured questionnaire was also prepared to gather demographic data. The info was tabulated and analyzed in terms of objectives of the study using descriptive and inferential statistics.

\section{RESULT}

The results show that Most of the samples (42\%) were between the age group of 3650years, regarding gender $82 \%$ sample was female Majority of the samples (84\%) were males and whereas only $(16 \%)$ were females, regarding education Majority of the samples had primary education (38\%) and $(58 \%)$ had date of diagnosis between 7-12 months, regarding type of treatment $83 \%$ sample were treated with chemotherapy, regarding family support majority of sample having family support.(Table 1)

According to association between demographic variable and depression scale, Age, Gender, Time of duration, mode of treatment were found non significant where as education, family support were found significant at 0.05 


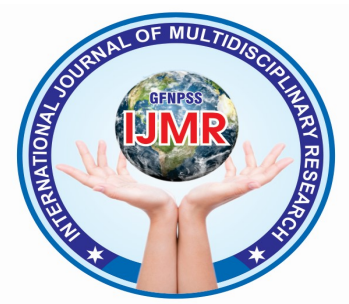

level of significant. (Table 2)

According to depression rating scale, majority of sample $65(54 \%)$ had mild depression followed by $38(31 \%)$ had no depression, 17(15\%) moderate depression and none of sample in severe depression stage . (Table 3).

Table: 1 - Frequency and percentages of distribution of socio - demographic variables of samples.

$n=120$

\begin{tabular}{|c|c|c|c|}
\hline S.No. & Demographic Variables & $\begin{array}{l}\text { Freq } \\
\text { uency }\end{array}$ & $\begin{array}{l}\text { Percentage } \\
(\%)\end{array}$ \\
\hline 1 & Age in years & & \\
\hline a) & 25 to 35 & 38 & 31 \\
\hline b) & 36 to 50 & 50 & 42 \\
\hline c) & 50 to 65 & 20 & 17 \\
\hline d) & 66 and above & 12 & 10 \\
\hline 2 & Gender & & \\
\hline a) & Male & 22 & 18 \\
\hline b) & Female & 98 & 82 \\
\hline 3 & Education & & \\
\hline a) & Illiterate & 42 & 35 \\
\hline b) & primary school & 46 & 38 \\
\hline c) & High school & 18 & 15 \\
\hline d) & Higher secondary school & 14 & 12 \\
\hline 4 & Date of diagnosis & & \\
\hline a) & $<6$ month & 30 & 25 \\
\hline b) & 7-12 months) & 70 & 58 \\
\hline c) & 13-24 months & 20 & 17 \\
\hline 5 & Mode of treatment & & \\
\hline a) & Chemotherapy & 100 & 83 \\
\hline b) & Radiation therapy & 12 & 10 \\
\hline c) & Combination & 8 & 7 \\
\hline $\begin{array}{l}6 \\
\text { a) } \\
\text { b) }\end{array}$ & $\begin{array}{l}\text { Availability of Family } \\
\text { support(Self reported) } \\
\text { Yes } \\
\text { No }\end{array}$ & $\begin{array}{l}116 \\
4\end{array}$ & $\begin{array}{l}97 \\
3\end{array}$ \\
\hline
\end{tabular}

Table 2: Association between demographic variable and levels of depressions

\begin{tabular}{|c|c|c|c|c|}
\hline $\begin{array}{c}\text { DEMOGRAPHIC } \\
\text { VARIABLES }\end{array}$ & $\begin{array}{c}\text { OBTAINED } \\
\text { CHI-SQUARE } \\
\text { VALUE }\end{array}$ & DF & ' $p$ ' & $\begin{array}{c}\text { INFERENC } \\
\text { E }\end{array}$ \\
\hline Age & 2.7518 & 3 & 0.732 & $\begin{array}{l}\text { Non- } \\
\text { significant }\end{array}$ \\
\hline Gender & 1.3672 & 1 & 0.242 & $\begin{array}{l}\text { Non- } \\
\text { significant }\end{array}$ \\
\hline education & 10.403 & 3 & 0.015 & Significant \\
\hline Time of duration & 0.7051 & 2 & 0.702 & $\begin{array}{l}\text { Non- } \\
\text { significant }\end{array}$ \\
\hline Mode of treatment & 5.2123 & 2 & 0.073 & $\begin{array}{l}\text { Non- } \\
\text { significant }\end{array}$ \\
\hline $\begin{array}{l}\text { Availability of } \\
\text { Family support }\end{array}$ & 4.6827 & 1 & 0.030 & Significant \\
\hline
\end{tabular}

Table 3: Levels of depression in cancer patients

\begin{tabular}{|c|c|c|}
\hline $\begin{array}{c}\text { Levels of } \\
\text { Depression }\end{array}$ & $\mathbf{N}$ & \% \\
\hline Normal & 38 & 31.6 \\
\hline Mild & 65 & 54.1 \\
\hline Moderate & 17 & 14.16 \\
\hline Server & 0 & 0 \\
\hline
\end{tabular}

\section{DISCUSSION}

A previously conducted study stated that no significant difference between age, gender, illness duration and mode of treatment and presence of depression. Our research also enforces majority of these conclusions by that research but at the same time conflicts with only one of the aforementioned factors. In our research, 


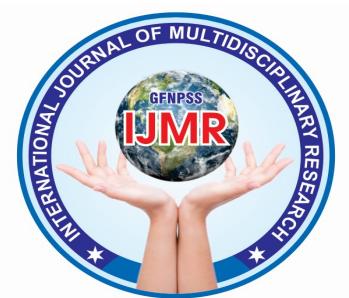

the education of the patient was found to have significance to the presence of depression and anxiety.

This study, we have assessed the level of depression among cancer patients and the demographic factors associated with it we have found depression of cancer patients dependent on level of education and family support. Depression among cancer patient having batter educational level was reduced when it compared to those who have no formal education. This finding is supported by a study from China ${ }^{11}$ and Greece $^{12}$

The reason may be these patients may have a have early screening and understanding of the disease which lead increases their recovery rate. Higher family support was strongly associated with to lower levels of depression and rapid recovery of depression and this finding support by a prospective study conducted by Kamen $\mathrm{C}$ et al. ${ }^{13}$

Our findings suggested with Swastika Garg et al level of depression level of depression 38(31\%) had no depression, 65 (54\%) had mild depression, 17(15\%) moderate depression and non of sample in severe depression stage ${ }^{14}$

One another study state that prevalence of major depressive disorder was around $8.33 \%$ in cancer patients (breast). This finding was associated with radiation therapy, pain severity and family support. $^{15}$

\section{CONCLUSION}

The prevalence of depression amongst patients with cancer was high while education and family support remained an important significant factor for it. Our research shows the importance of counseling for anxiety and depression to the patients as means of effectively improving their psychological disorders and ultimately improving the quality of medical care provided in the field of oncology. Recent research has reiterated the prevalence of anxiety in cancer patients and identified subpopulations who warrant closer scrutiny. Further research is essential, as well as the education of oncology healthcare professionals and family practitioners with regard to at-risk patients, and the importance of a psychological well being of cancer clients. Communication with the patient remains the main diagnostic approach to assessing anxiety. A discussion on the reasons for the patient's anxiety can lead to an understanding of how the patient perceives the disease, how she is coping and to 


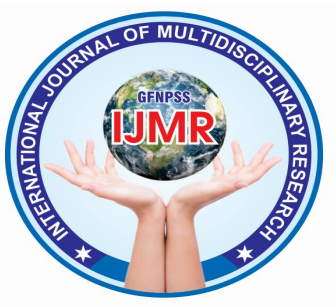

identify symptoms for diagnosis.

\section{REFERENCE}

1. Shatrughan Pareek, Narendra

Kaushik. Depression as co-morbidity among diabetes patients in India:

An increasing disease burden.

Indian J Surg Nurs, 2018; 7(3): 75-

77.

2. Pareek Shatrughan, Mehta Santosh, Goyal Harindarjeet. A structured teaching programme to assess the knowledge and practices of cancer patients regarding Radiotherapy induced skin reactions: A Quasi Experimental study. Int. J. Nur. Edu. Res. 2017; 5(2): 198-202. doi: 10.5958/2454-2660.2017.00043.6

3. Kumar S, Pareek S. Impact of videoassisted teaching programs regarding hand hygiene among oncology nurses. MGM J Med Sci 2021;8:131-5

4. Smith HR. Depression in cancer patients: Pathogenesis, implications and treatment (Review). Oncol Lett. 2015 Apr;9(4):1509-1514. doi: 10.3892/ol.2015.2944. Epub 2015 Feb 9. PMID: 25788991; PMCID: PMC4356432.

5. Onyeka TC. Psychosocial issues in palliative care: a review of five cases.
Indian J Palliat Care. 2010

Sep;16(3):123-8. doi: 10.4103/09731075.73642. PMID: 21218001;

PMCID: PMC3012234. Thus, individual counseling on how to live with their disease are necessary.

6. Board PS and PCE. Depression (PDQ®). PDQ Cancer Inf Summ [Internet]. 2016 Mar 28 [cited 2021 Sep 16]; Available from: https://www.ncbi.nlm.nih.gov/books/ NBK65970/

7. Pasquini M, Biondi M. Depression in cancer patients: a critical review. Clin Pract Epidemiol Ment Health. 2007 Feb 8;3:2. doi: 10.1186/1745-0179-32. PMID: 17288583; PMCID: PMC1797173.

8. Ghazavi Z, Feshangchi S, Alavi M, Keshvari M. Effect of a FamilyOriented Communication Skills Training Program on Depression, Anxiety, and Stress in Older Adults: A Randomized Clinical Trial. Nurs Midwifery Stud. 2016 Feb 20;5(1):e28550. doi: 10.17795/nmsjournal28550. PMID: 27331053 ; PMCID: PMC4915212.

9. Malla A, Joober R, Garcia A. "Mental illness is like any other medical illness": a critical examination of the 


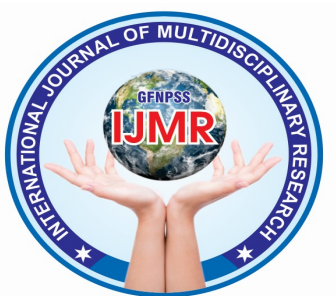

statement and its impact on patient care and society. J Psychiatry Neurosci. 2015 May;40(3):147-50. doi: 10.1503/jpn.150099. PMID: 25903034; PMCID: PMC4409431.

10. Board PS and PCE. Depression (PDQ®). PDQ Cancer Inf Summ [Internet]. 2016 Mar 28 [cited 2021

Sep 16]; Available from:

https://www.ncbi.nlm.nih.gov/books/ NBK65970/

11. Hong J.S. and Tian J., Prevalence of anxiety and depression and their risk factors in Chinese cancer patients. Supportive care in cancer, 2014. 22(2): p. 453-459.

12. altalataTorres M.A., et al., Predictors of depression in breast cancer patients treated with radiation: role of prior chemotherapy and nuclear factor kappa B. Cancer, 2013. 119(11): p. 1951-1959.
13. Kamen C, Cosgrove V, McKellar J, Cronkite R, Moos R. Family support and depressive symptoms: a 23-year follow-up. J Clin Psychol. 2011;67(3):215

14. Swastika Garg, Anupama Garg. A Study to Assess Depression among Cancer Patients at Our Tertiary Care Hospital Ajmer: An Hospital Based Study. Int J Med Res Prof. 2020 Jan; 6(1):16-18.

DOI:10.21276/ijmrp.2020.6.1.005 15. Su JA, Yeh DC, Chang CC, Lin TC, Lai CH, Hu PY, Ho YF, Chen VC, Wang TN, Gossop M. Depression and family support in breast cancer patients. Neuropsychiatr Dis Treat. 2017 Sep 13;13:2389-2396. doi: 10.2147/NDT.S135624. PMID: 28979126; PMCID: PMC5602463 